\title{
Un marxismo para los movimientos sociales o hacia una teoría crítica de la modernidad
}

Facundo Nahuel Martín (UBA/CONICET)

Resumen: En este trabajo intentaré una breve discusión con el pensamiento de Laclau a partir de la relectura categorial de Marx propuesta por Moishe Postone. Laclau impugna toda pretensión de enmarcar lo político en una lógica social preexistente, considerando que la sociedad está en sí misma estructurada a partir de una operación hegemónica. Este planteo, sin embargo, presupone que hay una pluralidad de demandas como punto de partida de la construcción hegemónica. Desde la lectura categorial de Postone, sostendré, puede interrogarse en cómo la lógica del capital, ligada al retroceso de los vínculos de dominación personal, es precondición de la proliferación de demandas particulares que caracteriza a la sociedad moderna. La modernidad del capital está estructurada a partir de lazos sociales anónimos, abstractos y cuasi-objetivos, que posibilitan precisamente que los particulares experimenten una contingencia y pluralidad peculiares (aunque limitadas) en sus formas de existencia. Finalmente, analizaré el caso particular de las relaciones de género en el capitalismo, partiendo de la lectura categorial del capital y sus formas de mediación social.

Palabras clave: Laclau; Postone, capitalismo, género. 
Abstract: In this paper I will try a brief discussion with Laclau from the standpoint of Moishe Postone's categorial reading of Marx. Laclau rejects any attempt to frame politics within a preexisting social logic, considering that society itself is structured by a hegemonic operation. Himself presupposes, however, that there is a multiplicity of demands, as a starting point for the hegemonic construction. Adressing the categorial reading, I wil argue, it is possible to inquire on how the logic of capital, linked to the decline of personal domination bonds, is a prerequisite of the proliferation of specific demands that characterizes modern society. Capitalist modernity is structured by anonymous, abstract and quasi-objective social ties, which allow precisely that individuals experience particularity, contingency and plurality (albeit limited) within its forms of existence. Finally, I will discuss the particular case of gender relations in capitalism, based on the reading categorial capital and its forms of social mediation.

Keywords: Laclau, Postone, Capitalism, Gender.

\section{Introducción}

En los últimos años, en particular desde las tribunas posmarxistas, se ha lanzado una serie de diatribas contra el pensamiento versado en Marx en sus diferentes expresiones. La crítica posmarxista sostiene que el marxismo, del que se considera superador, sería un esencialismo del sujeto, se fundaría en una filosofía cerrada de la historia y tendría presunciones subrepticiamente totalitarias. Hoy asistiríamos a una irremediable "crisis del marxismo", que no podría dar cuenta de la pluralización de los sujetos del antagonismo social (ruptura con la centralidad del proletariado), de la narrativa histórica (ruptura con la filosofía de la historia universal) y de las metas emancipatorias (ruptura con la promesa de construir una sociedad reconciliada consigo mismo).

Me detendré particularmente en la idea de que existe una pluralidad de sujetos, que desarrollan procesos de conflicto social, que no pueden reducirse a la lucha de clases entendida en sentido acotado como lucha protagonizada por el movimiento obrero y centrada en los salarios, las condiciones de trabajo, etc. En los últimos años, las agendas políticas de la izquierda habrían experimentado un creciente "descentramiento" de la clase trabajadora como actor privilegiado de los conflictos. "Nuevos movimientos sociales" o "nuevos antagonismos", centrados en políticas de la identidad o la subjetividad, en reivindicaciones étnicas, culturales y de género, u organizados desde ámbitos como el territorio, han tendido a desplazar la centralidad incontestable del trabajo proletario como sujeto global y fundamental de la lucha social. Esto, según los posmarxistas, rompería con toda pretensión de fundar una política crítica o emancipatoria en la precedencia de una lógica social objetiva. Ante los nuevos movimientos sociales, sería necesario apelar a una teoría contingencialista de la política, que parta de una pluralidad no determinable de antemano de expresiones de antagonismo. La idea misma de una lógica social mediada por las categorías del capital como sujeto social, por ende, debería abandonarse definitivamente. Intentaré discutir esta 
tesis posmarxista, pero dando un rodeo que revisite las categorías mismas de Marx y la crítica de la economía política, para reinterpretarlas como categorías comprehensivas de la totalidad social y su dinámica.

En el primer apartado del trabajo reconstruiré algunos planteos de Ernesto Laclau sobre la gestación de articulaciones hegemónicas a partir de una pluralidad de demandas no centradas socialmente. Interrogaré cuáles son las condiciones históricas (según el propio Laclau) para que emerja una proliferación de demandas, a su vez susceptibles de articulación hegemónica. Sobre esa base, intentaré mostrar que Laclau presupone algunas transformaciones históricas de importancia, que se dieron con el pasaje a la sociedad capitalista. Laclau apela al concepto de Lefort de "revolución democrática" (1990) como precondición histórica que enmarca la emergencia de una pluralidad contingente de demandas. Presupone, pues, una teoría no clarificada de la lógica y dinámica de la sociedad moderna, como aquella sociedad en la que, en virtud de la "revolución democrática", se desarrolla una multiplicidad de luchas particulares no centradas en un eje socialmente determinado. Sostendré que la propia "revolución democrática" puede vincularse con algunos estudios marxistas sobre la lógica del capital y las transformaciones que ésta impone en las formas de mediación social.

En un apartado posterior presentaré la "lectura categorial" que Moishe Postone (1993) hace de Marx. Esta teoría crítica del capital y la dinámica de la sociedad moderna, sostendré, puede dar cuenta de la proliferación de demandas y la emergencia de "nuevos" puntos de antagonismo social, no necesariamente centrados en el trabajo. Una lectura centrada en las categorías de la crítica de la economía política, comprendida no como una acotada teoría económica sino como "una etnografía de la sociedad capitalista llevada a cabo desde adentro" (Postone, 1993: 18) puede iluminar no sólo la lucha de clases o la dinámica de la acumulación, sino también fenómenos de la subjetividad, la construcción de identidades y otros procesos ligados a las formas sociales de mediación.

Completaré las referencias recuperando los estudios de Roswitha Scholz y John D'Emilio, que se centran en particular en las formas de patriarcado capitalista (Scholz) y en la historia del movimiento gay desde el punto de vista de la difusión del trabajo asalariado (D'Emilio). Sobre esta base, sostendré que los textos maduros de Marx encierran los fundamentos de una integral teoría crítica de la modernidad que pone el acento en el conflicto entre las potencialidades liberadoras y las recurrencias opresivas gestadas en la sociedad capitalista. Los "nuevos antagonismos" o "nuevos movimientos sociales", así, pueden interpretarse desde una perspectiva no reduccionista versada en el pensamiento de Marx. 


\section{Laclau: una pluralidad de antagonismos sociales}

La unidad de análisis más elemental de la dinámica política, según Ernesto Laclau, es la demanda. Hay una originaria proliferación de demandas particulares en el plano de la discursividad, proliferación que puede, llegado el caso, ser articulada de manera hegemónica, dando lugar a una identidad popular. La realidad social, estructurada discursivamente, se compone para Laclau de ensambles diferenciales, de una pluralidad de posiciones particulares que componen un sistema de diferencias donde cada una se define por las relaciones que mantiene con las otras. Estas posiciones diferenciales dada constituye una pluralidad de demandas particulares. Aprehender la totalidad de ese sistema diferencial es lo mismo que aprehender sus límites, contraponiéndola a algo otro que ella misma. Sin embargo, como se trata de la totalidad del sistema de diferencias, ese otro-limitante no puede ser una simple posición diferencial en su seno (pues no cumpliría el rol de alteridad constitutiva) ni tampoco una exterioridad completa (pues estamos lidiando con la totalidad de las posiciones diferenciales). Luego, el "afuera" que constituye el sistema total de diferencias debe ser un elemento excluido, que la totalidad expulsa de sí para constituirse. Ante este elemento excluido, todas las particularidades del sistema que se le opone son equivalentes: sin cancelar las diferencias entre ellas mismas, todas se delimitan por igual del otro que hace posible la totalidad. La construcción de una cadena de equivalencias, por lo tanto, subvierte (sin suprimirlas) a las posiciones diferenciales entre demandas, componiendo una identidad popular en la tensión entre la lógica diferencial y la lógica de la equivalencia. Por ende, la totalidad social se construye como una totalidad tensionada constitutivamente, levantada sobre la tensión entre las dos lógicas (diferencial y equivalente). La totalidad es necesaria para la construcción del campo discursivo de lo social (la expulsión de un otro-antagónico es condición de posibilidad de la estructuración de lo social como tal), y a la vez, como totalidad, es inherentemente fallida (pues nunca suprime la tensión entre equivalencia y diferencia). Finalmente, una diferencia particular, sin dejar de ser tal, asume la representación de la totalidad, que empero le es inconmensurable. Así se constituye el particular hegemónico. Para hegemonizar la cadena de equivalentes, la demanda del caso se vacía crecientemente de contenido propio, constituyéndose en "significante vacío" que representa la totalidad imposible-necesaria del sistema de posiciones diferenciales (Laclau, 2005: 69-72).

Pueden destacarse dos condiciones que enmarcan el análisis laclausiano. Por un lado, la imposibilidad de realizar una totalidad plena, transparente y reconciliada, es un límite ontológico de lo social. Por otro lado, la existencia de una proliferación de demandas plurales y heteróclitas parece una precondición histórica de la construcción hegemónica. En este trabajo me detendré en este segundo punto. La existencia de una pluralidad de demandas particulares se relaciona con la emergencia de los llamados "nuevos movimientos sociales", que precisamente darían por tierra con la vocación de construir un sujeto político determinado a priori por la lógica social. Dada la 
pluralidad de demandas y la diversidad de posiciones de sujeto como punto de partida, no parece haber un sujeto privilegiado como centro de la lucha política.

Ahora bien, ¿de dónde provienen las demandas? ¿Hay condiciones históricas para su emergencia? La multiplicación de demandas sociales se inscribe en la "revolución democrática" como fenómeno originario de las sociedades modernas. Hay, pues, precondiciones históricas para la política hegemónica. La comunidad campesina medieval, por ejemplo, sería escasamente susceptible de articulación hegemónica, pues su espacio social parece estar tan suturado que no habilitaría articulaciones diferenciales. Sin negar la presunción ontológica de que lo social es insusceptible de totalización, Laclau afirma que las sociedades premodernas serían relativamente más saturadas que las modernas. No habría entonces márgenes discursivos para la proliferación de demandas: el sistema de diferencias sería demasiado rígido y jerárquico para ello.

Una situación en la que un sistema de diferencias estuviera muy soldado internamente, implicaría el fin de la forma hegemónica de la política. En ese caso habría relaciones de subordinación o de poder, pero no, estrictamente hablando, relaciones hegemónicas (...) La dimensión hegemónica de la política sólo se expande en tanto el carácter abierto, no-saturado de lo social, se incrementa. En una comunidad campesina medieval, el área abierta a articulaciones diferenciales es mínima y, por lo tanto, allí no hay formas de articulación hegemónica (...). Es por esto que la forma hegemónica de la política sólo se vuelve dominante con los tiempos modernos, cuando la reproducción de diferentes áreas sociales tienen lugar en condiciones sociales permanentemente cambiantes (Laclau y Mouffe, 2001: 138, cursivas agregadas).

Si "la pluralidad no es el fenómeno a analizar, sino el punto de partida del análisis" (Laclau y Mouffe, 2001: 140), empero parece que la propia pluralidad de demandas diferenciales es en sí misma un producto histórico. Siguiendo a Lefort (1990), la revolución francesa marcaría "la mutación decisiva en el imaginario político de las sociedades occidentales" (Laclau y Mouffe, 2001: 155). La proliferación de demandas diferenciales se inscribe sobre la difusión generalizada del "discurso democrático". La revolución democrática es el "marco" [framework] para la lógica de desplazamientos democráticos (Laclau y Mouffe, 2001: 168). Paradójicamente, la propia pluralidad de demandas supone un contexto general que la posibilita, contexto estructurado por el propio principio democrático: "sólo desde el momento cuando el discurso democrático pasa a estar disponible para articular distintas formas de subordinación, van a existir las condiciones para hacer posible la lucha contra distintos tipos de desigualdad" (Laclau y Mouffe, 2001: 155). La revolución democrática, que desplaza las articulaciones sociales saturadas de la sociedad feudal, es la mutación decisiva del pasaje a la modernidad y posibilita la pluralidad de posiciones de sujeto que está a la base de toda la lógica hegemónica. "La diferencia radical que la sociedad democrática introduce es que el sitio del poder se convierte en un espacio vacío, desaparece la referencia a un garante trascendente" (Laclau y Mouffe, 2001: 186). 
En el origen de la política moderna hay un radical vaciamiento de la instancia soberana (el pueblo soberano no es corporizado por un individuo determinado). Esto abre un "proceso interminable de cuestionamiento" donde la sociedad ya no puede ser fijada y controlada por un centro único. En suma, la pluralidad de demandas en un sistema diferencial, que aparece como punto de partida y "dato" originario en el análisis de Laclau, es en definitiva reconocida como un resultado histórico: sólo la política moderna, que ha sufrido el corte radical de la revolución democrática, facilita la proliferación de demandas.

El corazón del argumento posmarxista de Laclau radica en la tesis de que lo político, como articulación hegemónica contingente, instituye lo social de manera originaria. Contra lo que considera como el economicismo determinista del marxismo tradicional, antes de toda "lógica social", habría una institución política radical y contingente. Ahora bien, ¿qué pasaría si hubiera, a la vez, precondiciones lógico-históricas implícitas en la proliferación de demandas diferenciales, es decir, en el propio punto de partida de lo político? Indagando en el "misterio del origen de la demanda" (Waiman, 2013: 288) se filtran las claves para un redescubrimiento del marxismo que pueda lidiar con el desafío posmarxista. Como intentaré mostrar en la sección siguiente, la revolución democrática y la multiplicación de demandas particulares no son datos originarios, sino que pueden deducirse de la lógica del capital en su especificidad histórica.

\section{La especificidad histórica del capital y las mutaciones de la mediación social}

Omar Acha (2013) ha señalado que Laclau, por lo menos en sus textos posmarxistas, tiende a ocuparse sesgadamente de Marx, centrándose en una lectura discutible de la "Introducción" de 1859 y el Manifiesto, reduciendo el "marxismo" a una filosofía de la historia necesarista y progresista, una concepción obrerista de la lucha de clases y una metafísica totalizante. En otras palabras, Laclau reduce la tradición marxista a lo que Postone (1993) llama "marxismo tradicional". Waiman (2013) destaca también la "conveniente" omisión de tradiciones como la teoría crítica de la Escuela de Frankfurt en la recepción laclausiana del marxismo. Siguiendo especialmente a Postone, voy a tratar de presentar los rudimentos de una interpretación de Marx que rompe con esas tres asunciones de la lectura laclausiana (historicismo, obrerismo, totalismo) y por lo tanto podría sostenerse a la altura del cuestionamiento posmarxista. Esta lectura parte del análisis de las mutaciones en las formas de mediación social producidas por la sociedad capitalista en su especificidad histórica, analiza las contradicciones entre las lógicas opresivas del capital y sus potencialidades liberadoras, y apunta a la abolición de la totalidad capitalista.

La relectura de Marx propuesta por Postone rompe radicalmente con toda filosofía de la historia universal. No parte de una ontología necesarista ni de un historicismo progresista, sino de un análisis históricamente situado de la lógica del capital. Para Postone, con el capitalismo se 
da una mutación fundamental en las formas de mediación social. Esta mutación es contingente en su origen histórico: el capitalismo se gestó a partir de procesos espontáneos, no determinados por el desarrollo de las fuerzas productivas u otra lógica previa. Sin embargo, una vez instituidas las formas de sociabilidad del capital, éstas poseen efectivamente un dinamismo intrínseco y característico que opera como lógica inmanente de lo social. En otras palabras, esta lectura de Marx no apela a la idea de "materialismo histórico" como teoría general de la historia, sino que se centra en la crítica históricamente situada del capital: "las categorías de Marx son históricamente específicas" (Postone, 1993: 21; citas de traducción propia).

Postone no parte de la "perspectiva del trabajo" concebida como transhistórica, sino de un análisis del rol del trabajo como mediador fundamental de las relaciones sociales capitalistas. No parte de comprender al trabajo en general como fuente de toda riqueza humana para, desde ese punto de vista, cuestionar la "distribución" inequitativa de sus productos. En cambio, discute la forma de trabajo capitalista (trabajo dividido en concreto y abstracto, trabajo creador de valor) para mostrar que el trabajo en el capitalismo 1) produce un tipo históricamente específico de riqueza (que se expresa en riqueza material y valor) y 2) cumple un rol mediador y estructurante de la totalidad social, que no cumplía en otras sociedades.

Primero,

la 'teoría del valor trabajo' de Marx (...) no es una teoría de las propiedades únicas del trabajo en general, sino un análisis de la especificidad histórica del valor como forma de riqueza, y del trabajo que supuestamente lo constituye (Postone, 1993: 26).

El valor (y el trabajo que lo produce, trabajo dividido en concreto y abstracto) son categorías específicamente capitalistas, ligadas a la forma capitalista de riqueza. En el capitalismo, el valor (dependiente del tiempo de trabajo abstracto) es "una forma de riqueza históricamente específica, diferente de la riqueza material" (Postone, 1993: 124). A la vez, la dinámica inmanente de la sociedad moderna tiende a la constante reducción del trabajo humano directo en la producción, mediante la incorporación de tecnologías y otros desarrollos. Así, la sociedad capitalista tiene una dinámica característica por la cual crea cada vez más riqueza material, gastando cada vez menos trabajo humano. Esto genera un creciente anacronismo del valor (dependiente del "gasto" de trabajo) con respecto a la riqueza material producida, dando a la sociedad moderna su dinámica específica y contradictoria. Esta dinámica, a la vez, se basa en la forma capitalista de trabajo (trabajo dividido en un aspecto concreto y otro abstracto, trabajo creador de valor).

Segundo, el trabajo creador de valor está en el corazón de las estructuras fetichizadas que motorizan la dominación social en el capitalismo. "La forma característica de la dominación social en el capitalismo, de acuerdo con Marx, se relaciona con la forma del trabajo social" (Postone, 1993: 125). Se delinean así tres formas históricas fundamentales: 1) las sociedades basadas en la dependencia personal, sociedades "abiertas" donde las personas sufren relaciones de subordina- 
ción manifiesta; 2) la sociedad capitalista, donde la dominación social se da en términos de "independencia personal, en el marco de un sistema de dependencia objetiva" (Postone, 1993: 125). En esta sociedad, las relaciones sociales se han convertido en algo objetivo y autónomo con respecto a los individuos. No son "abiertamente" relaciones entre personas (como sí eran, por caso, las relaciones vasalláticas y las formas de pertenencia del individuo a la comunidad precapitalista). 3) Finalmente, el socialismo, como posibilidad de la "más completa realización posible de la libertad humana" (Postone, 1993: 127), que se relacionaría con la superación tanto de las formas de dominación abiertas precapitalistas, como de las estructuras de dominación abstracta del capital.

En el nuevo contexto, la naturaleza misma del vínculo social cambia. "Lidiamos con un nuevo tipo de interdependencia, uno que emergió históricamente de manera lenta, espontánea y contingente" (Postone, 1993: 148). En esta nueva forma de interdependencia social, el individuo no obtiene las cosas que necesita para vivir a partir de "relaciones sociales abiertas" con otros individuos, sino que "el propio trabajo -directamente o expresado en sus productos- reemplaza a esas relaciones, sirviendo como medio 'objetivo' mediante el cual los productos de otros son adquiridos" (Postone, 1993: 150). El trabajo no es mediado por relaciones interpersonales directas, "reconocibles" como tales, sino por una serie de estructuras que él mismo constituye. Las estructuras abstractas y cuasi-objetivas que organizan la dominación social en la modernidad están relacionadas de manera característica con la forma capitalista de trabajo.

El capitalismo se caracteriza por la dinámica de valor que pone valor, por la continua auto-reproducción ampliada del valor abstracto. Esto determina el carácter autonomizado de la mediación social capitalista: ésta no es gobernable por las voluntades de los individuos o grupos, sino que se mueve a sí misma de manera automática. El trabajo creador de valor, a la vez, es el fundamento de esa mediación social autonomizada. En sociedades precapitalistas, "las actividades laborales son determinadas, de modo acorde, como sociales y cualitativamente particulares" (Postone, 1993: 150), mientras que "en el capitalismo, el trabajo mismo constituye una mediación social" (Postone, 1993: 151). El trabajo reemplaza ahora los sistemas de interdependencia personal como articuladores fundamentales de la vida colectiva. Luego, "el trabajo en el capitalismo se convierte en su propio fundamento social" (Postone, 1993: 151).

Postone rompe con toda visión necesarista de la historia universal. No parte de concebir un sujeto global de la historia que gobernaría el movimiento de las etapas históricas en una dinámica ascendente y necesaria. No hubo una necesidad histórica en el pasaje al capitalismo: tal imagen de necesidad es, en todo caso, una apariencia retrospectiva (Postone, 1993: 129). En cambio, concibe específicamente a la sociedad capitalista como una totalidad históricamente determinada. La concepción marxiana de la historia, luego, "no puede aprehenderse adecuadamente como una concepción esencialmente escatológica en forma secularizada" (Postone, 1993: 79).

El carácter de totalidad de las relaciones capitalistas descansa sobre su independencia con respecto a los individuos: 
La forma social es una totalidad porque no es una colección de varios particulares sino que, antes bien, es constituida por una 'sustancia' general y homogénea que es su propio fundamento. En tanto la totalidad es auto-fundante, auto-mediadora y objetivada, existe en forma cuasi-independiente (...) El capitalismo, como es analizado por Marx, es una forma social con atributos metafísicos -los del Sujeto absoluto (Postone, 1993: 156).

El análisis de la mediación social, como intentaré mostrar enseguida, tiene grandes implicancias para la teoría laclausiana de la demanda y el horizonte más general de la "revolución democrática". El capitalismo espliega un proceso dual. El capitalismo genera la contraposición entre una universalidad abstracta y vacía de contenido, por un lado, y un individuo particular concreto, por el otro (Postone, 1993: 366). Los universales característicos de la modernidad, ligados a la presunción general y abstracta de la igualdad y la libertad del individuo, pueden relacionarse entonces con a crítica del capital históricamente situada. Esto implica, asimismo, que es necesario no desconocer las parciales potencialidades liberadoras generadas por la universalidad capitalista: "el análisis de Marx no considera que todos los modos de universalidad constituidos en el capitalismo estén atados necesariamente al valor" (Postone, 1993: 367). Bajo la difusión del valor y el trabajo como mediadores sociales, se genera la posibilidad de un proyecto emancipador que, a la vez, podría trascender al propio capital. Estos desarrollos apuntan a la posibilidad de una nueva universalidad, que ya no fuera una totalidad mediada por un sujeto global automático ni produjera, correlativaente, al individuo moderno que se contrapone a la totalidad. Crece, entonces, "la tensión entre el potencial de la dimensión de valor de uso en el capitalismo y la actualidad del mundo constituido por el valor" (Postone, 1993: 367). Se profundiza así la contradicción entre las posibilidades liberadoras y las persistencias opresivas en la sociedad capitalista, contradicción que es la base de la teoría crítica del capital y permite también dar cuenta de los límites y posibilidades del proyecto democrático moderno.

El planteo de Postone tiene enormes implicancias para el despliegue de una teoría categorialmente marxista de los nuevos antagonismos sociales y la correlativa multiplicación de demandas y posiciones de sujeto. Comprender la mutación capitalista de la mediación social nos permite dar cuenta de las nuevas formas de subjetividad (y de conflicto) que se abren con el capitalismo. La "revolución democrática" y la proliferación de demandas y posiciones de sujeto, así, pueden inscribirse en la transformación histórica capitalista de la mediación social. El eje de la revolución democrática es el desplazamiento de los centros encarnados de poder y su reemplazo por la abierta, vacía y dinámica soberanía popular, cuyo centro (el pueblo) no es encarnado por una entidad palpable. A partir del análisis de Postone se puede vincular esta revolución con el desplazamiento de los lazos personales como formas de mediación social, y su reemplazo por las coacciones abstractas y objetivas de la mercancía, el valor y el trabajo. La propia revolución democrática, así, no sería un fenómeno originario, sino un jalón más en el vasto proceso de transformación de las mediaciones sociales que acaece con el capitalismo. 


\section{Marxismo y subjetividad I: D'Emilio y la identidad gay}

En el apartado anterior intenté mostrar que el análisis de Postone sobre el pasaje de las formas de mediación social abiertas a las relaciones sociales mediadas por el trabajo en el capitalismo, permite dar cuenta del "misterio del origen" de la pluralidad de demandas en la modernidad, que Laclau toma como punto de partida. Los "nuevos movimientos sociales" y sus agendas centradas en la subjetividad o la identidad, si este análisis es correcto, no son ajenos a la lógica del capital y las mutaciones que ésta impone en la vida social. En este apartado intentaré desarrollar esta tesis siguiendo los estudios de D'Emilio (2006) sobre la historia del movimiento gay. Antes, enmarcaré la discusión en una lectura sobre la experiencia subjetiva de la modernidad a la luz de la mutación capitalista de las formas sociales.

La generación de una clase de trabajadores libres, desposeídos de los medios de producción y liberados de toda relación personal de dependencia (como el vasallaje, etc.) es precondición de la gestación del vínculo social del capital, garantizado por las constricciones impersonales, anónimas y universales/abstractas propias del intercambio generalizado. El individuo como trabajador libre e independiente, que se ve constreñido a vender su fuerza de trabajo en virtud de la lógica anónima del capital (y no de la violencia ejercida inmediatamente por la clase dominante), se gesta entonces a partir de las mutaciones del vínculo social difundidas por el capital. Bajo la sociedad capitalista, es la vigencia anónima y "abstracta" (independiente de contenidos particulares) del valor la que garantiza el nexo social. Ello significa, también, que el nexo social capitalista posibilita una multiplicidad de trayectorias de vida elegidas de forma independiente por los individuos, aún cuando esa multiplicidad y esa libertad estén mediadas por el carácter reificado de la auto-reproducción del capital. Asimismo, el capital habilita una mirada distanciada del individuo con respecto a su particular forma de vida. Como señala Slavoj Žižek:

Lo que yo soy, mi antecedente social o cultural concreto, es vivido como contingente, ya que en última instancia lo que me define es la capacidad universal y 'abstracta' de pensar o trabajar (...) O tomemos el ejemplo ya mencionado de la 'profesión': la noción moderna de profesión implica que yo me concibo a mí mismo como un individuo que no 'nació' directamente en su rol social" (Žižek, 2003: 114).

Autores como Agnes Heller han caracterizado la experiencia existencial de la modernidad a partir de la puesta en contingencia de toda forma de vida particular: "La persona contingente es un resultado histórico. En el proceso de deconstruir la formación social premoderna, los hombres y las mujeres han llegado a ser contingentes" (Heller, 1999: 35). La lectura que Postone hace de Marx permite situar, en continuidad con lo planteado por autores como Žižek o Heller, la emergencia de la contingencia moderna como un resultado de la lógica del capital, la imposición del trabajo libre y la universalización de las formas de producción. La época moderna parece ca- 
racterizarse como el tiempo de los universales abstracto-formales $\mathrm{y}$, correlativamente, como el tiempo donde lo particular aparece como contingente. Es el individuo libre del mercado el que se enfrenta a una multiplicidad de "opciones" de vida contingentes.

John D’Emilio muestra que hay una relación no lineal, pero significativa, entre el avance del sistema de trabajo libre y el desarrollo de la identidad homosexual en la historia de Estados Unidos en el último siglo. Los colonizadores europeos que se establecieron en el territorio norteamericano en el siglo XVII poseían en lo fundamental una economía doméstica de unidades familiares autosuficientes. Con la lenta penetración del capitalismo, el hombre fue abandonando progresivamente el trabajo doméstico para ingresar al trabajo asalariado. Transformaciones posteriores, como la guerra mundial, también abrieron el mundo del trabajo para la mujer. Todo esto condujo -lenta pero sostenidamente- a separar al individuo de los lazos familiares y permitirle desarrollar una vida privada independiente. La lenta disolución de la economía doméstica y su reemplazo por el marco "abstracto" del trabajo asalariado sentó las bases objetivas para que algunos individuos pudieran elaborar sus deseos y prácticas sexuales hacia la construcción de una identidad homosexual. En resumen, mientras que las prácticas homosexuales probablemente tengan un origen antediluviano, la homosexualidad como identidad personal es un producto histórico reciente y específicamente moderno:

La evidencia de los registros de la corte y la iglesia en la Nueva Inglaterra colonial indica que el comportamiento homosexual masculino y femenino existió en el siglo diecisiete. El comportamiento homosexual, sin embargo, es diferente de la identidad homosexual. Simplemente no había un 'espacio social' en el sistema de producción colonial que permitiera a los varones y a las mujeres ser gay. La supervivencia se estructuraba en torno a la participación en el núcleo familiar. Ciertamente había actos homosexuales -sodomía entre los varones, 'obscenidad' entre mujeres- en los cuales las personas se involucraban, pero la familia era tan dominante que la sociedad colonial carecía incluso de la categoría de homosexual o lesbiana para describir a una persona (D’Emilio, 2006: 64).

El análisis de Postone sobre la mutación del vínculo social en el capitalismo arroja luz sobre estas transformaciones de la experiencia social en la modernidad. Si la época moderna aparece como la época de la contingencia, como la época en que los individuos pueden elegir "libremente" su destino, la lectura categorial muestra que esa contingencia se funda históricamente en el trabajo libre/desposeído y está a la vez sometida a las constricciones estructurales de la acumulación de capital.

El capital subordina el nexo social inmediato de la comunidad, la familia (u otras formas de dependencia personal, como el vasallaje) al nexo social universal y abstracto del intercambio generalizado (lo que no significa que los lazos comunitarios dejen de existir sino que pierden el carácter de "mediadores" fundamentales de la vida social). Así se produce históricamente una forma de relación social sistemáticamente contradictoria, que reúne a los hombres pero se eleva como 
algo externo a ellos. El capital produce lo que Marx llama "formas antitéticas de la unidad social" (Marx, 1971: 87) en la medida en que "1) los individuos siguen produciendo sólo para la sociedad y en la sociedad" pero "2) que su producción no es inmediatamente social, no es the off-spring of association" (Marx, 1971: 86). El nexo social capitalista es un nexo antitético, desgarrado, bajo el que lo universal y lo particular se contraponen insalvablemente. La producción social global se alza como una fuerza independiente de los individuos, que oprime y subordina a todos por igual: "Los individuos están subordinados a la producción social, que pesa sobre ellos como una fatalidad, pero la producción social no está subordinada a los individuos y controlada por ellos como un patrimonio común" (Marx, 1971: 86).

El estudio de D'Emilio permite comprender el proceso dual del capital sobre el vínculo social. Por un lado, el reemplazo de formas de dominación personal o directa por el vínculo impersonal y reificado del capital totaliza las relaciones sociales bajo un sujeto global que constriñe las posibilidades de autodeterminación de las personas. Por el otro, las nuevas relaciones impersonales y cuasi-objetivas abren algunas nuevas posibilidades para los individuos, en la medida en que éstos pueden, si bien bajo el corset de la lógica del capital, elegir parcialmente sus trayectorias de vida de manera independiente.

Ahora bien, ¿no hay ningún lazo entre positivo entre la familia patriarcal, la norma heterosexual y el capitalismo? ¿La constricción capitalista de las posibilidades de autodeterminación social se limita al fenómeno abstracto de la reificación? Por el contrario, hay una relación intrínseca y contradictoria entre el capital y la familia patriarcal, en virtud de la cual aquél posibilita movimientos sociales que cuestionen a ésta, pero al mismo tiempo la legitima implícitamente como forma social dominante:

He argumentado que la relación entre capitalismo y familia es fundamentalmente contradictoria. Por un lado, el capitalismo continuamente debilita la fundación material de la familia, haciendo posible para los individuos vivir fuera de la familia, y para las lesbianas y varones gays se posibilita el desarrollo de su identidad sexual. Por otro lado, el capitalismo necesita empujar a varones y mujeres en la estructura de familia, al menos de manera suficientemente duradera como para producir la nueva generación de trabajadores/as. La elevación de la familia al punto de preeminencia ideológica garantiza que la sociedad capitalista reproducirá no solamente niños/ as, sino también heterosexismo y homofobia. En el más profundo sentido, el capitalismo es el problema (D'Emilio, 2006: 71).

D'Emilio sostiene, pues, que el capitalismo no se limita a pluralizar las trayectorias de vida de los individuos, una vez que es el lazo abstracto del valor el que garantiza la mediación social. Tampoco basta decir que el capitalismo pluraliza las relaciones sociales pero manteniéndolas bajo el molde abstracto de la reificación. En cambio, el capital impone específicamente la norma "familiar" y heterosexista como patrón social. El rol de la familia patriarcal como garante de la re- 
producción de la fuerza de trabajo es fundamental en este punto. Para comprender esto, recurriré a los planteos de Roswitha Scholz sobre la división del valor y el patriarcado en el capitalismo.

\section{Marxismo y subjetividad II. Scholz y el patriarcado capitalista}

Para comprender el vínculo entre patriarcado y capitalismo tenemos que desembarazarnos de una representación habitual, según la cual la devaluación social de la mujer es ante todo un resabio feudal, rémora de formas de dominación precapitalistas que la modernidad del capital vendría a desterrar. Esta representación heredada supone, más o menos, que la sociedad capitalista es igualitaria en sus cimientos, de modo que la desaparición final de la dominación de género es en definitiva sólo una cuestión de tiempo: el "desarrollo" del capital traerá, a largo plazo, las condiciones para la liberación femenina. El patriarcado sería simplemente un remanente de tiempos pretéritos en proceso de desaparecer. No es antojadizo que se piense así: esta lectura se basa, si bien de manera distorsionada, en determinaciones efectivas de la lógica capitalista. La sociedad capitalista es, a diferencia de otras formas de dominación históricas, compatible -paradójicamente- con la igualdad formal de las personas. Como reconstruí en el apartado dedicado a Postone, con el capitalismo se da un pasaje de formas de dominación personales o directas a formas de dominación impersonales y cuasi-objetivas. La sociedad asume así la forma de una totalidad auto-moviente, que se opone a los particulares como si fuera una objetividad ajena, dotada de un movimiento automático. Estas estructuras cuasi-objetivas e independientes de las personas, mediadas por el trabajo abstracto, se constituyen sobre la base de la disolución de las formas precapitalistas de dominación, basadas en jerarquías directas o personales de grupos o de individuos sobre otros. La transformación de la lógica fundamental de la dominación hace que la igualdad se convierta en un principio jurídico normal en el capitalismo. La dominación específica del capital, en otras palabras, aparece como la dominación de estructuras universales y anónimas que suprimen las formas directas de poder personal.

A pesar de la aparente compatibilidad histórica entre las formas de sociabilidad del capital y la difusión de la igualdad formal entre las personas, la dominación patriarcal parece insistir decididamente en nuestras sociedades. Como si la lógica "premoderna" del patriarcado persistiera a pesar de la supuesta tendencia del capital a la igualdad, garantizada por la disolución de los lazos tradicionales de dependencia personal y la erección de las nuevas formas cuasi-objetivas de mediación social. Precisamente, el feminismo marxista de Scholz permite interpretar esta tenaz "persistencia" de la dominación sobre las mujeres, mostrando que no se trata de una rémora del pasado, sino que el capital genera una forma de patriarcado que le es característica. Así, puede desmentirse la imagen ingenua según la cual la dominación sobre las mujeres sería puramente un resabio precapitalista, sosteniendo que el capital genera sobre sus propias condiciones una particular forma de patriarcado. 
Scholz sostiene que el capitalismo es una forma históricamente específica del patriarcado, al que podemos llamar "patriarcado productor de mercancías". Su punto de partida coincide con el de Postone, en torno a la mutación histórica de las formas de dominación en el capitalismo: "En las sociedades premodernas (...) se producía bajo otras relaciones de dominación (personales en vez de cosificadas por la forma de la mercancía) y principalmente para el uso" (Scholz, 2014: 48). En el capitalismo, la dominación se funda en la subordinación de las personas, sus capacidades y sus necesidades a la dinámica "tautológica" del capital que se autovaloriza, como "sujeto automático" basado en "mecanismos anónimos ciegos" (Scholz, 2014: 48), antes que en la violencia física directa ejercida por un grupo. La novedad de su análisis radica en que pasa de la crítica del valor a la crítica de la escisión del valor [Wert-Abspaltung]:

Con el valor o el trabajo abstracto no queda suficientemente especificada la forma fundamental del capitalismo en cuanto relación fetichista. También habría que dar cuenta del hecho de que en el capitalismo se producen actividades reproductivas que realizan sobre todo las mujeres. De acuerdo con esto, la escisión del valor remite a que las actividades reproductivas identificadas sustancialmente como femeninas, así como los sentimientos, los atributos y actitudes asociadas con ellas (emocionalidad, sensualidad, cuidado, etc.), están escindidos precisamente del valor/trabajo abstracto. Así pues, el contexto de vida femenino, las actividades reproductivas femeninas tienen en el capitalismo un carácter diferente al del trabajo abstracto; por tanto no se las puede subsumir sin más bajo el concepto de trabajo (Scholz, 2014: 49).

En otras palabras, la constitución de la lógica "abstracta", anónima y cuasi-objetiva de dominación en el capitalismo, que puede vincularse con la universal proclamación de la igualdad en la modernidad, sin embargo se monta sobre una forma específicamente capitalista y moderna de dominación patriarcal. Esta dominación se estructura a partir de la "escisión del valor" que masculiniza y jerarquiza el trabajo asalariado al tiempo que feminiza y desvaloriza las actividades reproductivas. Marx y Engels, por su parte, sentaron las bases de la crítica del valor pero desconocieron su articulación con esta división, que está en la base de la reproducción de la fuerza de trabajo y por lo tanto forma parte de las condiciones de posibilidad de la acumulación de capital. La dominación patriarcal tiene, claro, una historia premoderna, pero "con la universalidad de la forma de la mercancía alcanzó una cualidad completamente nueva" (Scholz, 2014: 50). El capitalismo se monta lógicamente sobre una división patriarcal de las actividades humanas, que asocia el trabajo creador de valor a la masculinidad (y a una serie de valores socialmente masculinizados, como la eficiencia, la competitividad, la agresividad); al tiempo que degrada y feminiza las actividades reproductivas, que aportan de manera indirecta a la reproducción de capital y se asocian a una serie de valores considerados femeninos, como el cuidado, la ternura, el afecto o incluso la irracionalidad. El capitalismo puede así ser considerado como un patriarcado productor de mercancías, que erige un completo proyecto civilizatorio de dominación masculina: 
Podría hablarse de manera algo exagerada del género masculino como del 'género del capitalismo'; y, desde este trasfondo, cabría decir que una comprensión dualista de masculinidad y feminidad es la concepción dominante del género en la modernidad. El modelo civilizatorio productor de mercancías tiene su condición de posibilidad en la opresión de las mujeres (Scholz, 2014: 51).

La escisión del valor, evidentemente, no es estática sino que asume una serie de formas históricas variables. En los actuales tiempos "posmodernos", por caso, las mujeres se ven sometidas a una doble socialización: al tiempo que siguen siendo responsables de los cuidados y las actividades reproductivas en el hogar, participan también del trabajo asalariado fuera de casa. Según Scholz, esto no hace estallar completamente a las relaciones de género capitalistas, sino que las flexibiliza en un marco que no altera las bases formales de la Wert-Abspaltung [escisión del valor] estructural. De modo análogo, puede decirse que la propia categoría de valor no es estática, sino que sufre mutaciones a través de diferentes configuraciones históricas capitalistas, que empero no alteran su nervio lógico fundamental. La división del valor, que está en la base de la constitución de la propia categoría de valor, posee también una variabilidad histórica.

En síntesis, en este apartado intenté mostrar que el capitalismo no sólo disuelve los lazos de dominación personal basados para instituir un nuevo tipo de vínculo social objetivado, anónimo y abstracto. La sociedad capitalista instituye también un tipo de dominación masculina que le es característica, ligada a la separación entre el trabajo creador de valor (masculinzado) y las actividades reproductivas (feminizadas). A continuación, en la conclusión, intentaré repensar el significado de la teoría crítica de la sociedad a partir de estos análisis.

\section{Conclusiones}

En este trabajo describí cuatro movimientos. Primero, reconstruí algunas coordenadas del pensamiento de Laclau. Su teoría política pretende romper con la primacía de las relaciones sociales por sobre la construcción hegemónica. La emergencia de un significante hegemónico que articule lo social es, según este planteo, contingente; al tiempo que no hay criterios a priori para determinar la prioridad de una de las demandas por sobre el resto. Intenté mostrar que la proliferación de demandas de la que parte Laclau (enmarcada en la "revolución democrática") es susceptible de interrogación y análisis desde el punto de vista de la lógica del capital. Siguiendo a Postone, sostuve que el capitalismo se caracteriza por el pasaje de relaciones sociales abiertas (basadas en formas directas de dependencia) a relaciones sociales fetichistas y reificadas, donde las compulsiones abstractas y anónimas del valor y el trabajo mediatizan el vínculo social. A partir de ese pasaje, aparecen los parámetros de la política moderna, que incluye entre otras cosas la emergencia de una pluralidad de trayectorias de vida para las personas, vivenciadas efectivamente como contingentes. Luego, siguiendo a D'Emilio, intenté mostrar la importancia de la mutación 
capitalista de las formas de nexo social para dar cuenta de la construcción de la identidad gay. Sostuve que la difusión del trabajo asalariado incrementa, hasta cierto punto, la independencia del individuo con respecto a la familia y otras autoridades personales, lo que facilita que las personas desplieguen trayectorias de vida personales contingentes y construyan su identidad sobre esa base. En el apartado final retomé los planteos de Roswitha Scholz sobre el patriarcado capitalista. La autora muestra que el capitalismo no compone únicamente una forma social reificada y anónima, sino que está asociada a una muy característica dominación particularista de los varones sobre las mujeres. El capitalismo, en efecto, se gestó a partir de la escisión de las actividades humanas entre trabajo productor de valor (masculinizado) y actividades reproductivas o de cuidado, devaluadas y feminizadas. Esa escisión original configura un patriarcado productor de mercancías históricamente determinado, donde las formas abstractas e impersonales de mediación social, garantizadas por el valor, vienen a su vez ligadas a lógicas de una peculiar (específicamente capitalista) dominación de los hombres sobre las mujeres.

Lo anterior significa que el capitalismo, desde el punto de vista de una lectura categorial, puede comprenderse como un proceso complejo y fundamentalmente contradictorio donde se dan tres fenómenos concomitantes. Primero, a partir de la mutación de las formas de nexo social y la construcción de una mediación anónima fundada en el trabajo y el valor, se despliega un proceso sin precedentes (históricamente determinado) de reificación de las relaciones sociales. Las relaciones capitalistas, a diferencia de otras formas históricas previas de articulación social, se fundan en las coacciones anónimas y cuasi-objetivas del valor. Al mismo tiempo, puesto que estas coacciones son objetivas y anónimas, "liberan" al individuo de las formas precapitalistas de dependencia, habilitando una novedosa pluralización de las trayectorias de vida de cada uno. Una vez que el trabajo y el valor garantizan la articulación de la sociedad, las relaciones de dependencia directa que otrora ataban al individuo a la familia o la autoridad retroceden en importancia, lo que permite, hasta cierto punto, que las personas experimenten sus vidas particulares como contingentes y susceptibles de alteración. El origen histórico de la pluralidad de demandas de las que parte Laclau puede situarse, pues, en la mutación capitalista de las formas de mediación. Finalmente, la crítica de Scholz a la escisión del valor permite comprender que la dominación en el capitalismo no se reduce a los procesos anónimos, abstractos Y cuasi-objetivos de la reificación, sino que también está asociada a muy peculiares formas de dominación particularista. En efecto, la escisión del valor, que feminiza y devalúa las actividades reproductivas, está en el origen del patriarcado capitalista. Esto puede relacionarse, también, con la necesidad que tiene el capitalismo de sostener a la familia como unidad de reproducción, al tiempo que la socava por su propia dinámica.

Bajo esta relectura, pues, es posible dar cuenta de una pluralidad de demandas particulares en la sociedad moderna desde una perspectiva articulada con la crítica del valor y la mercancía como categorías mediadoras de la vida colectiva. En este caso me he detenido en las identidades de género y las disidencias sexuales, y otros análisis específicos deberían proseguir el trabajo para dar cuenta de otras formas de antagonismo social. Una vez que comprendemos las catego- 
rías marxianas en toda su amplitud, como categorías estructurantes de las formas de mediación social y la subjetividad, los llamados "nuevos movimientos sociales" pueden ser comprendidos desde un punto de vista fundado en la crítica de la economía política y sus conceptos. Esto, a la vez, permite dar cuenta de la génesis histórica de la "pluralidad de demandas" que otros análisis, como los de Laclau, dan por sentadas como punto de partida sin ulterior análisis. Así, puede sostenerse que una adecuada relectura de Marx puede superar la diatriba posmarxista y dar cuenta, en términos ligados al valor, el trabajo y el capital (y su crítica) de aspectos comprehensivos y significativos de la sociedad moderna.

Finalmente, esta relectura permite pensar nuevamente el significado de la teoría crítica de la sociedad. La sociedad capitalista ha gestado tanto formas dominación como las condiciones de posibilidad para cuestionar esa dominación. Se puede, entonces, formular una crítica inmanente de la dominación capitalista, tanto de la dominación por estructuras impersonales abstractas, como de las formas de dominación particularista que surgen con la modernidad del capital. El capital genera, en términos generales, no sólo las posibilidades de su propia superación histórica como capital, sino también las posibilidades para superar las dominaciones particularistas que le han sido asociadas. La teoría crítica, en este contexto de reformulación parcial, apunta en una doble dirección. Por un lado, aspira a superar las coacciones abstractas y objetivadas que estructuran al capitalismo en sí mismo. Por el otro, se dirige contra las formas de dominación particularista que se han asociado históricamente a la dominación del capital y que componen con éste un sistema flexible y mutable. No se trata sólo de discutir cómo las personas son oprimidas por un sistema de coacciones fetichizado, sino también de poner en cuestión los privilegios de grupo que ese sistema de coacciones reforzó y reformuló históricamente.

\section{Bibliografía}

Acha, O. (2013). Del populismo marxista al postmarxista: la trayectoria de Ernesto Laclau en la Izquierda Nacional (1963-2013). Archivos de Historia del Movimiento Obrero Y la Izquierda, 3, pp. 5063, Buenos Aires.

Arthur, C. (2004). The New Dialectic and Marx's Capital. Londres: Brill.

D’Emilio, J. (2006). Capitalismo e identidad gay. Nuevo topo. Revista de historia Y pensamiento crítico, 2, pp. 60-72, Buenos Aires.

Geras, N. (1988). Ex-Marxism without Substance: Being a Real Reply to Laclau and Mouffe. New Left Review, Londres, 169, mayo-junio, pp. 34-61.

Haug, F. (1996). Frauen-Politiken. Berlin: Argument.

--- (2006). Hacia una teoría de las relaciones de género. En Borón, A. et al. (comps.). La teoría marxista hoy. Problemas y perspectivas. Buenos Aires: CLACSO. 
Kurz, R. y Trenkle, N (1999). Die Aufhebung der Arbeit. Ein anderer Blick in das Jenseits des Kapitalismus. En Kurz, R., Lohoff, E. y Trenkle, N (eds.), Feierabend! Elf Attacken gegen die Arbeit, Hamburg.

Lefort, C. (1990). La invención democrática. Buenos Aires: Nueva Visión.

Laclau, E. (1996). Emancipación Y diferencia. Buenos Aires: Ariel.

--- (2005). On Populist Reason. Londres y Nueva York: Verso.

Laclau, E. y Mouffe, C., (2001). Hegemony and socialist strategy. Londres y Nueva York: Verso.

Martín, F. (2014). Marx de vuelta. Hacia una teoría crítica de la modernidad. Buenos Aires: Editorial El Colectivo.

Marx, K. (1971). Elementos fundamentales para la crítica de la economía política (Grundrisse) 18571858. Tomo I. México DF: Siglo XXI.

Meiksins Wood, E. (1986). The Retreat from Class. A New "True" Socialism. Londres: Verso.

Rancière, J. (2007). El desacuerdo. Política y filosofía. Buenos Aires: Nueva Visión.

Postone, M. (1993). Time, Labor and Social Domination. A Reinterpretation of Marx's Critical Theory. Cambridge: Cambridge University Press.

--- (2006). History and Helplesness. Public Culture, Duke, nº 18, v. 1, pp. 93-110.

--- (2009). History and heteronomy. Critical Essays. Tokio: UTCP.

Waiman, J. (2013). Dialéctica y ontología: repensando el antagonismo post-marxista en la teoría crítica. Constelaciones. Revista de teoría crítica, 5, pp. 280-310, Madrid. Publicación virtual: http:/l www.constelaciones-rtc.net/05/05_16.pdf (22/07/2015 último acceso)

Scholz, R. (1999). Wert und Geschlechterverhältnis. Publicación virtual: http://www.exit-online.org/ textanzl.php?tabelle=autoren\&index=21\&posnr=37\&backtext1=text1.php

--- (2014). El patriarcado productor de mercancías. Tesis sobre capitalismo y relaciones de género. Constelaciones. Revista de Teoría Crítica, 3, pp. 44-60, Madrid. Publicación virtual: http://www. constelaciones-rtc.net/05/05_04.pdf (01/07/2015 último acceso).

Trenkle, N (2008). Afustieg und Falls des Arbeitsmanns. Publicación virtual: http://www.krisis. org/2008/aufstieg-und-fall-des-arbeitsmanns

Žižek, S. (2003). ¿Lucha de clases o posmodernismo? Sí, por favor. En Butler, J., Laclau, E. y Žižek, S., Contingencia, hegemonía Y universalidad. Diálogos contemporáneos en la izquierda. México DF: Fondo de Cultura Económica. 
Facundo Nahuel Martín: Facultad de Filosofía y Letras (UBA) - CONICET. Corre-o electrónico: facunahuel@gmail.com. El autor es becario doctoral del CONICET, docente y estudiante doctoral de la Facultad de Filosofía y Letras de la Universidad de Buenos Aires. Investiga cuestiones relacionadas con el marxismo y la teoría crítica de la sociedad, especialmente el pensamiento de Theodor W. Adorno. Es autor del libro Marx de vuelta. Hacia una teoría crítica de la modernidad. 